\title{
Arquitectura y urbanismo informales en La Habana contemporánea: configuración, problemas y repercusiones en la cultura
}

JANICE ARGAILLOT

> Doctora en estudios hispanófonos (especialidad: civilización latinoamericana). Profesora contractual de la Universidad de Cergy-Pontoise, Francia. Laboratorio CICC (Civilisations et Identités Culturelles Comparées). Grupo de investigación: GRIAHAL (Groupe de Recherche Interdisciplinaire sur les Antilles Hispaniques et l'Amérique Latine). janice.argaillot@orange.fr

Universidad de Valparaíso

Facultad de Arquitectura

Márgenes

Espacio Arte Sociedad

Arquitectura y urbanismo informales en La

Habana contemporánea: configuración, pro-

blemas y repercusiones en la cultura

Diciembre 2012, Vol. 9, № 11

pp. 115-125

ISSNN 0718-4034

Recepción: Agosto 2012

Aceptación: Diciembre 2012

\section{RESUMEN}

Este artículo propone un análisis de la arquitectura y del urbanismo llamados informales en La Habana contemporánea. Se mostrará que tales construcciones no se sitúan sólo en las afueras de la capital cubana, y que la informalidad urbanística puede tomar varias formas. Por otra parte, se estudiarán los problemas planteados por los barrios informales, no sólo a nivel sanitario, sino también en lo referente a la identidad de sus habitantes. En fin, se observarán los impactos de la informalidad arquitectónica en la cultura. PALABRAS CLAVE

La Habana, arquitectura, barrios, informal, cultura

Architecture and informal town planning in contemporary Habana: configuration, problems and impacts on culture

ABSTRACT

This article offers an analysis of the architecture and urbanism designated as informal in contemporary Habana. We will show that these constructions not only can be found in the periphery of the Cuban capital, and that town-planning informality can take various forms. In addition, we will study the problems generated by the informal districts, at a sanitary level as well as concerning the identity of their inhabitants. Finally, we will observe the impacts of architectonic informality on the culture.

KEY WORDS

Habana, architecture, districts, informal, culture

Architecture et urbanisme informel dans la Havane contemporaine: configuration, problème et répercussion dans la culture

RÉSUMÉ

Cet article propose une analyse de l'architecture et de l'urbanisme appelés informels dans La Havane contemporaine. Nous montrerons ces constructions ne se situent pas uniquement en périphérie de la capitale cubaine, et que l'informalité urbanistique peut prendre plusieurs formes. Par ailleurs, nous étudierons les problèmes posés par les quartiers informels, non seulement au niveau sanitaire, mais aussi en ce qui concerne l'identité de leurs habitants. Finalement, nous observerons les impacts de l'informalité architectonique sur la culture.

MOTS-CLÉS

La Havane, architecture, quartiers, informel, culture 


\section{INTRODUCCIÓN}

Los movimientos de liberación y revolución que tuvieron lugar en América Latina hicieron de la existencia de ciudades informales y asentamientos marginales la prueba de una división social, que ciertos observadores presentan como la división inducida por el capitalismo (Del Real \& Scarpaci, 2011, p. 70). En Cuba, baluarte anticapitalista, tal división puede sorprender, ya que se considera que la Revolución mejoró las condiciones de vida de los cubanos, y particularmente la vivienda en las grandes ciudades. No obstante, quedan graves problemas, incluso en el centro de la capital. Así, este artículo propone un análisis del urbanismo y de la arquitectura informal en La Habana y sus inmediaciones.

Nos concentraremos primero en la localización de los espacios informales, para mostrar que la ciudad formal y la ciudad informal son vecinas. Veremos así que la informalidad puede tomar varias formas, e intentaremos entender lo que se entiende por La Habana informal. En segundo lugar, insistiremos en los problemas planteados, no sólo a nivel sanitario, sino también en lo referente a la identidad de los que viven en barrios presentados como informales.

En fin, interrogaremos los impactos del urbanismo informal en la cultura. En efecto, y quizás de manera sorprendente, lo informal, cuando se relaciona con la arquitectura y el urbanismo, puede ser el resultado y al mismo tiempo la base de cierta cultura.

\section{LA HABANA INFORMAL: ¿DÓNDE? ¿CÓMO? ¿QUÉ ES?}

Ante todo, hay que señalar que la informalidad arquitectónica se relaciona casi siempre con el subdesarrollo:

La antítesis entre la ciudad formal y la informal será una de las principales características en las metrópolis de los países subdesarrollados. El Caribe no escapa a este proceso, aunque en una escala menor que las dramáticas condiciones existentes en el territorio continental: Ciudad de México, San Pablo o Buenos Aires. El tamaño reducido de las islas no permite la existencia de megalópolis del Primer Mundo: sólo La Habana, en las Antillas, posee una estructura urbana compacta y continua, similar a las restantes capitales latinoamericanas (Segre, 2003, p. 220).

Esto se puede discutir, en la medida en que incluso en países tradicionalmente considerados como desarrollados se observa la conformación de espacios informales. Sea lo que sea, se observa que la fragmentación entre una ciudad formal y otra informal es bastante característica de las megalópolis latinoamericanas. La elección de La Habana para nuestro estudio se explica aquí por su especificidad dentro del área caribeña, que hace de ella una ciudad aparte y que la relaciona con las tierras continentales -de tal modo que la informalidad ya no es sólo una característica, sino también un lazo.

Hay que precisar que entre 1930 y 1950, en el Caribe, La Habana, San Juan y Santo Domingo se distinguían por la trama ordenada de su trazado (Segre, 2003, p. 178). Parece pues que La Habana se construyó históricamente como un espacio ordenado, y el orden se opone muy a menudo a la informalidad. No obstante, la capital cubana recibió los impactos de varios procesos políticos, y su informalidad se creó en reacción a decisiones políticas que tenían como meta preservar el poder establecido:
Difícil sería dilucidar si los asentamientos marginales en América Latina aparecieron por primera vez en La Habana o en Rio de Janeiro. [...] en 1897 [...] el cruel gobernador general español Valeria Weyler i Nicolau, ante el avance del Ejército Libertador a lo largo de la isla, decidió expulsar a los campesinos de sus tierras y concentrarlos en las ciudades para quitarles el apoyo logístico a los combatientes cubanos. A La Habana llegaron cien mil personas, instaladas en terrenos periféricos en improvisados cobertizos de yaguas o ramas, sin agua ni letrinas. Según el cónsul norteamericano, al año ya habían muerto por tifus, viruela, disentería y cólera, casi la mitad de los residentes (Segre, 2005, p. 121).

Sin quererlo, el propio gobierno revolucionario contribuyó a tal proceso. En efecto, el principio de la Revolución fue marcado por un esfuerzo masivo a nivel de la cultura, y La Habana se impuso como capital cultural del proyecto político en curso. Numerosos estudiantes fueron traídos a y atraídos por la capital: Havana played a key role, often immeasurable in the early educational efforts of the revolution. For example, thousand of Havana families took in student boarders who came from eastern Cuba to study in the capital. Massive scholarship programs have also brought an overflow of students to the city (Scarpaci \& Segre \& Corula, 2002, p. 286).

El problema es que no se pudieron construir viviendas para acoger a todos los estudiantes o todos los que querían descubrir la ciudad. Se sabe que los flujos de población modelan el espacio urbano, y hoy, un 50 a $60 \%$ de los habitantes de la Habana Vieja viene de otros lugares (Del Real et al., 2011, p. 62). Lo importante aquí es ver que todo el espacio de la ciudad fue conquistado por la informalidad, a causa de movimientos migratorios - sobre todo internos. Las dificultades económicas del país también influyen en este punto, y la crisis global vivida por la Isla significa igualmente una crisis de la vivienda.

Se tiene que notar que los barrios informales están presentes en toda la isla, y tanto en la periferia de la capital cubana como en su centro: En toda la isla florecen como setas barrios marginales más propios de un país como Brasil [...] (Botín \& Bassets, 2009, p. 58). Eso puede sorprender, ya que se tiende generalmente a considerar que la informalidad se empuja hacia las afueras, como para esconderla; pero en el mismísimo centro histórico habanero, las barbacoas son muy numerosas: The Housing and Population Census of 1995 [...] concluded that 51.4 percent of the buildings in the historic center had been transformed with barbacoas, approximately 10.813 buildings. This represents 7.580 housing units of forty-five square meters, or 37.942 rooms of nine square meters (Del Real et al., 2011, p. 62). Una barbacoa es una plataforma construida en el interior de una vivienda ya existente (Del Real et al., 2011, p. 63), o sea que se trata de una añadidura a la ciudad preexistente. Su aspecto informal se relaciona evidentemente con la ilegalidad, ya que su construcción misma se realiza fuera de la ley:

In contemporary Cuban society the barbacoas are illegal and informal constructions. They are illegal because the government does not officially recognize or sanction these constructions. They are informal because rarely do these enterprises get any form of technical or design assistance by professionals sanctioned by state institutions. In this dual condition of illegality and informality, the barbacoas share similar instances and characteristics with other 
forms of illegal and informal settlements, like the favelas in Rio de Janeiro, the ranchos of Caracas, the villas miseria in Buenos Aires or the barriadas and pueblos jóvenes in Lima (Del Real et al., 2011, p. 69).

Se ve otra vez que la informalidad parece constituir un hilo de Ariadna entre numerosos países latinoamericanos, y que si dicha informalidad tiene particularidades -es decir que se vive de diferentes maneras según el lugar-su presencia por lo menos en todas las grandes ciudades del subcontinente puede ser visto como un vínculo entre los pueblos.

Volveremos sobre la importancia de la ubicación de las barbacoas, pero ya podemos notar que se trata de una forma de vivienda cuya construcción se conoce, mas no se reconoce. En efecto, las autoridades, al no poder fomentar la creación de viviendas necesarias para satisfacer la demanda, consideran las barbacoas como ilegales, pero no pueden impedirlas ni destruir todas las que ya se levantaron. Además, existen varios tipos de viviendas informales en La Habana. Allende las barbacoas evocadas arriba, se pueden citar los Ilega y pon: Los Llega y Pon son barrios de chabolas construidas con tablas, chapas de zinc, cartones..., toda una panoplia de materiales de desecho para dar cobijo a los miles de desempleados que acuden a la capital con la esperanza de encontrar trabajo [...] (Botín et al., 2009, p. 58).

Lo de construir con materiales de desecho ya marca cierta informalidad, porque significa que se construye un barrio o una vivienda con lo que los otros pusieron de lado o rechazaron, y se construye a consecuencia una frontera invisible entre espacio normal y espacio marginal. Además, se observa que la elevación de barrios informales es finalmente la respuesta más rápida a la urgencia supuesta por la llegada masiva de nuevos habitantes: Hoy por hoy el diagnóstico de la ciudad en la periferia "global" revela una situación que cada vez se aleja más de lo que podemos considerar sostenible: crece la ciudad informal, al tiempo que se asiste a una hiperinflación urbana (Gaja i Díaz, 2005, p. 161).

Pero la informalidad urbanística habanera no está constituida únicamente por chabolas, sino que también proviene del abandono de ciertos barrios, inclusive barrios turísticos bastante frecuentados:

En el caso de Cuba, aunque la situación difiere del resto del Caribe en cuanto al volumen de los cinturones marginales de las ciudades, cada vez se hace más patente la falta de mantenimiento contractivo del entramado urbano; dicho aspecto en la ciudad de La Habana es uno de los factores de importancia en cuanto a los riesgos que se perciben en el futuro inmediato y a mediano plazo, se estima que más del $70 \%$ de las viviendas en la ciudad se encuentran en mal estado constructivo y una buena parte de las mismas están en estado crítico (Fernández, 2007, p. 327).

De este modo, podemos decir que la falta de mantenimiento de edificios hasta entonces formales -debida a las dificultades económicas del país- desemboca en la creación de un espacio informal, abandonado a veces por sus habitantes históricos, en el que la delincuencia y la marginalidad toman importancia. El problema es tal, que hoy día se pueden ver las casuchas del barrio de la Timba en la mismísima Plaza de la Revolución, [...] frente al Teatro Nacional (Botín et al., 2009, p. 59). La informalidad se impone pues en cada parte, y de varias maneras.
Por otro lado, la informalidad urbanística cubana es un proceso inscrito en la continuidad. Para decirlo de otro modo, se constata que la construcción de barrios informales desde el principio de la Revolución no fue un hito puntual, sino que se extiende en el tiempo. Sin embargo, el observador puede clasificarlos, ya que ciertos se consideran como barrios antiguos, y otros como barrios recientes: Algunos de esos repartos, como Casablanca, situado en el municipio de Regla, frente a la bahía de La Habana, tiene casi 20 años de antigüedad; otros son más recientes, como El Bachiplán, en La Habana del Este; Blumer Caliente, en Boyeros, y San Miguel, en San Miguel del Padrón; pero todos están cortados por el mismo patrón, son villas miseria, como las de cualquier ciudad de Latinoamérica (Botín et al., 2009, p. 58-59). Esto significa que el proceso no parece poder ser parado, y se tiene que relacionar con el crecimiento demográfico del país. Además, se observa la manera con que ciertos barrios informales llegan a convertirse en barrios conocidos de todos, y cómo llegan a ser duraderos en el tiempo.

Puesto que existen varios tipos de vivienda informal, y que los barrios informales se construyeron en diferentes épocas y lugares, surge una desigualdad entre ellos. En efecto, aparece como una graduación entre éstos, que permite clasificarlos ya no a partir de su género o tiempo de existencia, sino de las condiciones de vida que ofrece. Hasta en la condición de informalidad, existen grados o categorías, y ciertos barrios se perciben como peores que otros:

Although the generic term slum (or tugurio in spanish) is seldom used in Cuba, there are several ways that substandard housing is described: by housing type, housing conditions, building materials, and settlement type. This roughly coincides with the UN category of "poor structural quality" but takes in a broader range of indicators. The Iocation of different types of slum housing is also important. The Cuban government regards three housing types as inherently substandard -tenements, rural thatched-roof bohios, and improvised units. The typical inner city slum dwelling unit is a room in a tenement, known by the terms ciudadela, cuartería, casa de vecindad, pasaje, or solar. It is usually a single room with shared bathing and sanitary facilities in a common courtyard or passageway, although such rooms are often upgraded and expanded to include indoor plumbing. The great majority of these single-room units are located in older multifamily buildings in Havana's central areas. But individual, stand-alone rooms are also found in the backyards of inner-city blocks and in outlying shantytowns. A "hybrid" between a tenement and a small shantytown appears when additions to a former mansion subdivided into rooms extend out into the backyard until they become individual units detached from the original building (Hamberg, 2011, p. 76).

En cuanto a los solares, se presentan como una repetición de la división social inducida por la esclavitud: Les solares étaient des immeubles construits après l'abolition de l'esclavage pour accueillir l'exode rural qu'elle avait provoqué. Divisés en logis exigus donnant sur des couloirs en balcon autour d'une grande cour centrale, ils rappelaient, dans leur structure, les barracones d'esclaves dans les plantations (Sefil, 2010, p. 241). Estos solares, que a veces se llaman ciudadelas o casas de vecindad, son pues un reflejo de la categorización de la sociedad impuesta por la colonización, y sobre todo de la fragmentación racial inducida por este proceso histórico. La marginación alcanza todas las capas de la población, pero se 

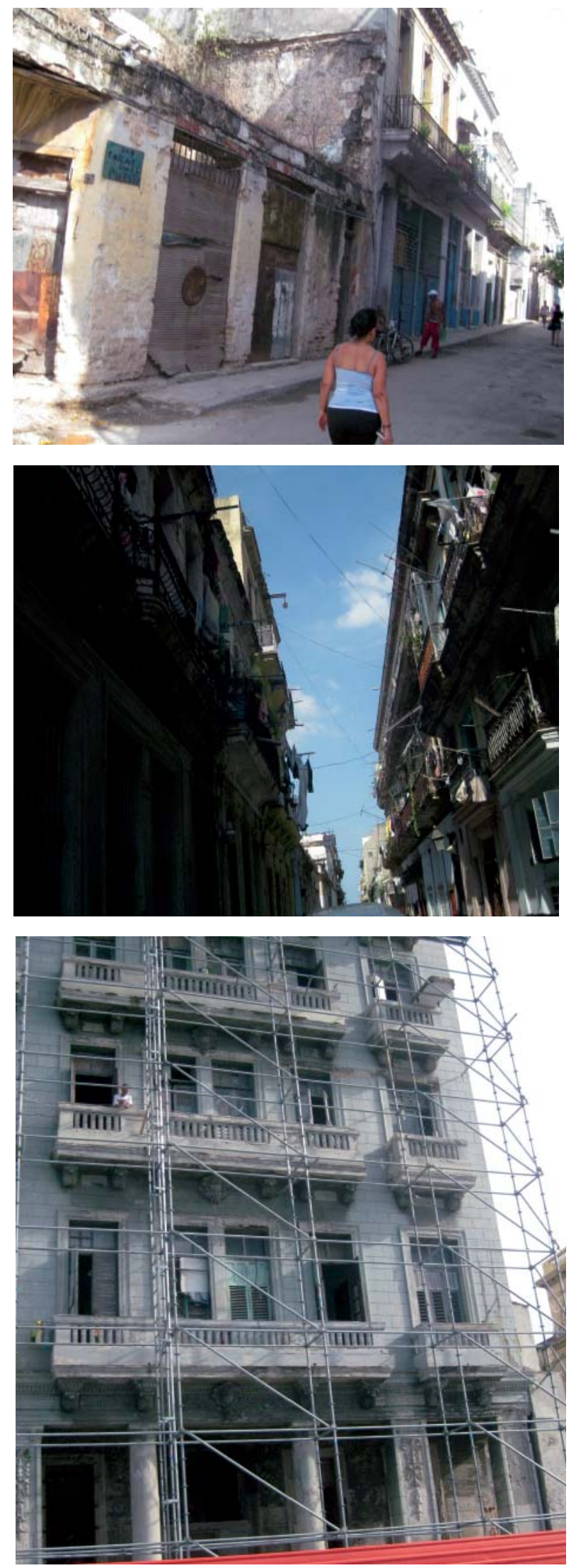

Imágenes 1, 2, 3. Los barrios de La Habana Vieja y Centro Habana. Obras de renovación del Malecón. Fuente: Janice Argaillot, julio de 2009 observa una tendencia a considerar que los Negros son los primeros habitantes de los solares.

Ya antes de la Revolución, se identificaban los solares como espacios negros, ligados a la marginalidad, el crimen y la promiscuidad (De la Fuente, 2001, p. 114). Si fueron originalmente construidos para amparar a los antiguos esclavos, su función original se perdió, y persistió en el imaginario común la idea de que estas construcciones eran insalubres a causa de sus habitantes. En realidad, ya se había marginalizado a éstos, quienes no tuvieron el mismo acceso que los demás a la sanidad por ejemplo.

A menudo, se precisa que una casa de vecindad tiene doce habitaciones, un solar entre veinte y treinta habitaciones, y una ciudadela más de cien (Scarpaci et al., 2002, p. 76). Otras veces, se dice que la terminología casa de vecindad es una apelación oficial, mientras solar o ciudadela son expresiones populares. La confusión semántica sin duda puede ser relacionada con el desconcierto o la perplejidad de la ciudad formal cuando mira a su vecina.

En paralelo, muchos observadores pusieron de realce que los albergues provisionales que facilita el Gobierno a los que se han quedado sin casa por los derrumbes (Botín et al., 2009, p. 57) no son más que guetos: Esos albergues, mucho peor que las cuarterías, son casuchas levantadas a toda prisa en eriales, a base de paneles prefabricados y una letrina común (Botín et al., 2009, p. 57). El espacio del cual uno dispone para vivir $-\mathrm{y}$ a consecuencia el grado de privacidad que puede esperar-aparece aquí tan importante como el material con que se construye la vivienda.

Ciertos observadores ponen aparte otros barrios, que presentan como pobres y marginales, tales como Romerillo, Palo Cargao o Las Yaguas (Botín et al., 2009, p. 59). Con esto se insinúa que la marginalidad no viene siempre relacionada con la pobreza, aunque el análisis de las condiciones de vida de los habitantes de los barrios informales pruebe el contrario.

\section{PROBLEMAS PLANTEADOS Y REVELADOS}

Se podría preguntar en qué es molestadora la arquitectura informal, y si se pueden emplear los términos arquitectura o urbanismo. El urbanismo muy a menudo se presenta como el arte y la ciencia de la construcción, mientras la arquitectura se limita al conjunto de edificios y casas levantados. Las construcciones informales precisamente se ven como construcciones que no tienen nada que ver con el arte, pero una vez más, todo es cuestión de definición y de punto de vista. En efecto, es la ciudad formal la que impone su visión de lo que puede ser el arte. Además, si la ciencia de la ciudad formal se basa en la tecnología, la de la ciudad informal se funda en cierta habilidad.

Parece que la informalidad, y su reflejo concreto, la arquitectura informal, cristalizan los miedos de la sociedad formal. En efecto, en el inconsciente colectivo, la informalidad se relaciona con la marginalidad y la ilegalidad, cada palabra teniendo sin embargo su definición así como límites:

[...] Luis Carlos Jiménez reúne los significados de informalidad, ilegalidad y marginalidad en una conjunción generada por aspectos como el de no cumplir con las normativas sociales y el de no tener las óptimas condiciones de infraestructura y bienestar; aspectos que en términos de desarrollo marginal se traducen en asentamientos de periferias urbanas y sectores de desigualdad social. Los linde- 
ros de lo informal, lo ilegal, lo clandestino y lo marginal se relacionan con significados diferentes: lo informal, que no cumple con la normativa existente, el concepto está dado desde la economía; lo ilegal, que transgrede las leyes que rigen la sociedad, el concepto se genera en lo legislativo; lo clandestino, lo que se hace por fuera de la sociedad, y finalmente lo marginal, referido a la condición de lugar, que por sus condiciones de ubicación, se encuentra fuera de la oferta de servicios y bienes comunitarios, pudiéndose decir que responde a un concepto geográfico (Hernández Castro, 2006, p. 32).

El barrio informal no cumple con las normativas sociales - por eso provoca temores entre los que residen en la ciudad institucional-y mezcla finalmente informalidad, ilegalidad, y clandestinidad. El primer problema que plantea es pues la impresión que da de escapar a todas las leyes. Dicho de otro modo, los barrios informales aparecen como lugares peligrosos, en los cuales todo puede ocurrir sin que los actores formales -tales como el Estado y las fuerzas policiales- puedan intervenir.

Igualmente, la informalidad urbanística es muy a menudo sinónimo de pobreza, y de infraestructuras deficientes. Así, los sectores de hábitat popular [...] de América Latina en general [...] son lugares altamente urbanizados pero con muchas costumbres rurales, su economía es casi artesanal e informal, pero su consumo es global, y en cuanto a lo tecnológico puede ser que las vías del barrio no estén pavimentadas o que los servicios públicos no cubran al $100 \%$ de los habitantes, pero existen viviendas con conexión satelital para televisión e Internet (Hernández García, 2008, p. 113). En el caso habanero, cabe notar que el barrio de Atarés falta de agua corriente (Botín et al., 2009, p. 58). La pobreza que se vincula a la ciudad informal proporciona una imagen poco afable de ésta: suciedad, delincuencia... Al no ser conectada a las redes de alcantarilla, o de tecnología, la ciudad informal da la impresión de vivir fuera del tiempo, y fuera de códigos ya no tan legales sino morales.

Los problemas ambientales inducidos por el urbanismo informal tampoco pueden ser pasados por alto. El no acceso al saneamiento tiene repercusiones tanto en la salud de los habitantes como en el medio ambiente. La ciudad informal se construye como un lugar de residencia temporal, provisional, transitoria, pero sus habitantes se instalan en realidad en una situación duradera. Esta antítesis entre permanencia y fugacidad, continuidad y fragilidad ocasiona cierto malestar entre los residentes de la ciudad formal, ya que este tipo de hábitat escapa a sus esquemas mentales.

El uso de material precario acarrea dos tipos de problemas: problemas sanitarios y problemas relacionados a lo efímero de las construcciones. En efecto, si, como ya lo hemos apuntado, los barrios informales tienen tendencia a sentarse duraderamente en el paisaje de la ciudad, las construcciones en sí están sometidas a riesgos climáticos por ejemplo. Si se reconstruyen poco a poco, y si no desaparecen los barrios en su totalidad, ciertas habitaciones se derrumban.

Por otra parte, es de notar que la arquitectura y el urbanismo informales aparecen como herramientas para estudiar la situación socioeconómica cubana. Así, la apertura al turismo y a la inversión extranjera (aunque sea de manera controlada) favorece la división social, la exclusión y la marginación. Se crea una sociedad de dos velocidades que aparece claramente cuando se estudia las condiciones de vida de la población. Los contrastes entre los que tienen acceso al CUC - peso convertible cubano, indexado en el valor del dólar estadounidense-y los que no tienen más que la moneda nacional (Scarpaci et al., 2002, p. 187) son en realidad una expresión de la zanja entre la ciudad formal y la ciudad informal:

Es evidente que frente a esta informalidad se produce una dicotomía entre dos ciudades, entre dos maneras de pensar y usar la ciudad: una formal acogida por las normas que regulan el crecimiento y la utilización del espacio urbano, y otra informal, donde no se cumplen las normas, con carencia de prácticamente todo, y con crecimiento urbano de supervivencia, espontáneo y al margen de la "otra" ciudad. Dicotomía esta que acompaña distintas formas de manifestación social y cultural que pretenden encontrar un espacio en la ciudad, una solución al problema de techo y de servicios (Hernández García, 2008, p. 35).

La economía informal es una marca distintiva de la ciudad (Izquierdo, 2002, p. 40), que apareció durante el siglo XVII a través de los portales. [...] Éstos prefiguran el auge de la economía informal [...] (Izquierdo, 2002, p. 40). Marcaron de forma duradera la cara de la ciudad, la utilización del espacio, y sobre todo su división: The porticoes that first appeared in the nineteenth century became an integral part of the city. Even today, city dwellers circulate under the shade of the portico, and street vendors huddle there to sell their wares. The latter foreshadowed the rise of the informal economy that would spawn in these same places (Scarpaci et al., 2002, p. 68).

Pero el abismo entre las dos ciudades, formal e informal, no sólo tiene que ver con la economía; ésta conlleva y acarrea una informalidad más global, pero el desfase entre el espacio formal y el informal también tiene vínculos con la cultura, la vida en sociedad. Y precisamente estos dos espacios no enfocan la ciudad del mismo modo. Así, viven juntas dos maneras de pensar y usar la ciudad, o sea dos maneras de vivir en comunidad y de utilizar el ambiente. El problema parece ser el de un choque cultural entre dos mundos, a los que se da, y quizás se imponga, aspiraciones diferentes. Si los diferentes problemas materiales y físicos (falta de agua, condiciones de vida miserables) parecen conducir a y/o sostener la economía informal -a manera de un verdadero círculo vicioso- el espacio formal o informal no remite sólo a un espacio concreto, tangible. La arquitectura y la urbanización informal determinan pues barrios informales, o de residencia informal, que a su vez abren el paso a otros espacios informales.

Así, y además de provocar problemas sanitarios, el urbanismo informal provoca problemas morales. Efectivamente, los barrios informales son la expresión concreta de la desigualdad, y eventualmente de la injusticia social. Pueden aparecer dudas en cuanto a la Revolución, así como cierto desinterés por la vida en comunidad, aunque lo informal también desemboca en solidaridad. Para decirlo de otro modo, la informalidad, al ser la concretización de una fractura social contra la cual la Revolución lucha desde 1959, puede conducir a cierta rebelión cívica. Plantea por lo menos en Cuba la cuestión de los logros esta Revolución, ya que la crisis de los años 1990, nacida del derrumbe de la Unión Soviética, dio a la clara que la vivienda no se había beneficiado de la misma atención por parte del gobierno revolucionario que la educación o la salud (Del Real et al., 2011, p. 62).

Sin embargo, las penurias y las dificultades económicas también revelaron la voluntad de los cubanos de luchar por su sistema político, su cultura, y su independencia; en tal sentido, las barbacoas 
pueden ser percibidas como la máxima expresión del apego del pueblo cubano a su Revolución - por los sacrificios que representan-y al mismo tiempo como la manifestación de todos los problemas actuales de la Isla: What is singular about the Cuban case is the prominence and the impact that these transformations have had on the city of Havana. More importantly, barbacoa construction represents the most meaningful type of new construction for the average Cuban who copes with a quotidian landscape full of uncertainty and penury (Del Real et al., 2011, p.69).

Sea lo que sea, la informalidad no es sólo un estado de hecho, algo abstracto; condiciona la vida de seres humanos, incluso en su vertiente más personal: El ser residente ilegal de la ciudad crea una barrera para la legalización de las uniones matrimoniales. Por otro lado, el saberse y asumirse como ilegales, el vivir como tales en todos, o una inmensa mayoría, de los actos de su vida, los condiciona como individuos, a disentir, en la libertad del amor, de la ley que los excluye y los margina (Rodríguez Ruiz. Estévez Mezquía. Cañet Iglesias, 2008, p. 240-241). Así, ser residente ilegal significa estar al margen, y plantea problemas hasta en la vida privada. Tal condición crea una pared, para no decir una muralla entre los individuos, e impide en cierta medida la comunicación y el intercambio. También significa vivir con una espada de Damocles arriba de la cabeza, al no tener título de pertenencia o documentación, y es por eso que la informalidad no sólo influye en la vida de los residentes, sino también en su construcción personal y en su manera de aprehender la o las ciudades que los rodean.

Se puede interrogar el impacto de estos barrios en el turista, así como la fuerza de los programas de rehabilitación de La Habana Vieja frente al crecimiento del urbanismo informal. En efecto, los folletos que promueven el turismo en la capital cubana insisten en la magia de La Habana Vieja, sin precisar la realidad que se vive ahí detrás de las paredes. Los esfuerzos concentrados en el barrio histórico, que es también el barrio capitalino turístico por excelencia, muestran la dicotomía entre ciudad formal y ciudad informal, entre lo que se quiere presentar al mundo, y lo que se quiere esconder.

De manera general en América Latina, hoy, los problemas del hábitat, de la vivienda y de la urbanización se sitúan en asuntos como la pobreza, las distintas formas de exclusión social y sus perspectivas del desarrollo, el desplazamiento, la migración, el reasentamiento e inserción la vida urbana, la transformación del espacio urbano informal y formal de la ciudad [...] (Torres Tovar, 2008, p. 139). Hay que precisar que los esfuerzos de los gobiernos latinoamericanos, emprendidos en los años 50 y 60, sólo beneficiaron a una parte de la población, y crearon asentamientos marginales (Del Real et al., 2011, p. 56).

El problema fue pues identificado desde muchos años, pero hasta los esfuerzos emprendidos para mejorar la vivienda acentuaron la barrera entre ciudad formal e informal. Las autoridades cubanas reconocen el problema, y en 2006 la revista semestral de antropología Catauro, muy minoritaria, [...] publicó [...] un exhaustivo Informe sobre la marginalidad en Cuba (Botín et al., 2009, p. 59). La situación no se esconde, pero el sistema cubano, aunque haya conocido mutaciones desde el año 2008 con la elección de Raúl Castro, impide por sí una verdadera apropiación del espacio urbano por parte de los habitantes. En efecto, la falta de un verdadero mercado inmobiliario y las permutas hacen de la vivienda un lugar de paso, finalmente de todos y compartido con la comunidad: In the city of Havana we observe that selected locations are being scooped up by national and joint-venture hotel and recreational companies. Since there is no formal real-estate market in socialist Cuba, residents must swap homes (permutarse) when trying to coordinate their work lives and their home (Del Real et al., 2011, p. 70).

La falta de recursos y los problemas ligados a la vivienda parecen ser unos de los mayores problemas de la Revolución, y la creación de una ciudad informal, marginal o marginada revela la dificultad de involucrar a toda la población en el proceso revolucionario. En paralelo, por falta de espacio, se imparten clases en museos; esto significa que el gobierno entiende la necesidad de aprovechar del más mínimo espacio.

Por otra parte, la situación geográfica de Cuba la somete a duras condiciones climáticas, que, al destruir los lugares de residencia, y combinados a los problemas económicos evocados, provocan cierta emergencia en cuanto al realojamiento, que a su vez provoca una informalidad que perdura: Los ciclones que azotan la isla de Cuba agudizan el deterioro de la viviendas, pero a pesar de los derrumbes, muy pocos quieren abandonarlas, como Victorio, protagonista de Los palacios distantes de Abilio Estévez, que recorre la ciudad en ruinas hasta hallar cobijo en un teatro abandonado. Es una obra de ficción, pero Victorio se parece mucho a Reinaldo, una persona de carne y hueso que vive desde años en el semiderruido teatro Capitolio, en Centro Habana [...] (Botín et al., 2009, p. 57). Los ejemplos son muchos, y demuestran que la informalidad de la vivienda a veces alcanza la formalidad: Vecina de Reinaldo es María, "la de la piscina", como la llaman, porque desde años vive precisamente en el hueco de la piscina situada en la azotea del antiguo hotel Bristol. Alli se construyó una chabola con cuatro tablas y algunas chapas, y nunca ha tenido problemas con la policía. Al contrario, María no está considerada como una "ocupa", está censada en esta "vivienda" y paga religiosamente los recibos del agua, la luz y el gas [...] (Botín et al., 2009, p. 57).

Si el gobierno cubano intenta realojar a las personas que se quedan sin casa después de catástrofes naturales o meteorológicas, y si no se puede negar la reacción rápida del gobierno cubano frente a situaciones de urgencia, la falta de recursos económicos conlleva la construcción de viviendas provisionales que se convierten en viviendas duraderas. De esta manera, el Estado participa sin quererlo en la construcción de lugares de vida no informales desde el punto de vista legal, sino más bien desde el punto de vista social, ya que son unos lugares inhóspitos de condiciones penosas (Botín et al., 2009, p. 58). Lo formal y lo informal se entremezclan, porque la gente que decide quedarse en los escombros sigue pagando lo que debe al Estado, que de tal manera contribuye a la supervivencia de barrios informales. Río Verde, cerca del aeropuerto José Martí, Luyanó y La Víbora, en el extrarradio de La Habana (Botín et al., 2009, p. 58), son ejemplos de este fenómeno.

Por supuesto, la informalidad arquitectural viene relacionada con la ocupación informal de los lugares. Dicha ocupación provoca mutaciones en el seno de la ciudad, que debe adaptarse al flujo de habitantes. Así, en La Habana, los camellos se convirtieron en el medio de transporte privilegiado de los pobres, y demuestran el pasaje de la informalidad a la vista de todos.

Pese a todo, se constata el apego de los habitantes a su barrio, aunque sea informal. Esto podría desconcertar, tanto más cuanto que la ciudad informal poco se estudió, y que se desconoce así la relación que su habitante tiene con ella: 
Tradicionalmente la ciudad popular o marginal no es objeto de estudios arquitectónicos, urbanísticos o estéticos, se entiende como un lugar no deseado y con muchos problemas, con poco o ningún atractivo para ser digno de estudiarse. Sin embargo, esta ciudad es mayoritaria en países de América Latina [...]. En estos sectores de ciudad el poblador establece una relación muy especial con su entorno, en gran medida porque ha sido él, a través de esquemas de participación individual o colectiva, planeada o espontánea, quien lo ha gestionado, muchas veces construido y siempre transformado (Hernández García, 2008, p. 9).

Así, sintiéndose constructor, arquitecto, e incluso artífice de su espacio, el habitante de la ciudad informal vive una relación espacial con su entorno, impregnada de cariño. Los habitantes de ciertos barrios informales manifestaron de forma muy concreta su apego a su lugar de vida: El 14 de junio de 2006, unos 60 vecinos de Casablanca se manifestaron en la Plaza de la Revolución para protestar porque iban a ser desalojados de sus viviendas. El hecho, insólito en Cuba [...] puso de manifiesto la voluntad de muchos ciudadanos de defender su derecho a la vivienda [...]. Uno de los vecinos dijo: "Tenemos libreta de abastecimiento, donamos sangre al comité y votamos por el delegado de la zona. Lo único que queremos es que nos dejen donde estamos" (Botín et al., 2009, p. 58). En otras palabras, los habitantes de Casablanca expresaron su voluntad de ser considerados como ciudadanos de pleno derecho. En su opinión, su implicación en la vida comunitaria les daba el derecho a seguir viviendo en su barrio, aunque fuese informal o marginal. Eso demuestra el lazo sentimental de los habitantes con su lugar de vida, en el cual pusieron esperanzas, para el que hicieron esfuerzos, y que intentan mejorar cada vez más.

Ahí surge otra vez el problema de la frontera entre formal e informal. En efecto, en la medida en que el gobierno dejó a esos ciudadanos ocupar el lugar, pidiéndoles además los mismos esfuerzos y la misma implicación que para cualquier otra comunidad, cualquier otra manzana, éstos no entienden por qué se intentaría sanear el barrio expulsándoles.

En un país como Venezuela, en la actualidad socio privilegiado de Cuba en América Latina, se desarrolló la Misión Vivienda, con la meta de construir viviendas sociales, que en verdad conoció un éxito de medio tono. Esto puede ser el punto de partida de una colaboración entre varios países, ya que la integración regional enfoca cada vez más los problemas de las poblaciones, y que al unirse, los Estados de la región caribeña podrían alcanzar realmente sus objetivos en materia habitacional. En Cuba, la asociación Habitat Cuba, creada en 1994, había desarrollado una intensa labor a favor de la mejora de la vivienda, implicando a los residentes. Sin embargo, el Gobierno cubano decretó su disolución en el 2001.

\section{IMPACTOS EN LA CULTURA}

Uno puede interrogarse sobre la relación entre ciudad, formalidad, informalidad y cultura. Parece que en el conjunto latinoamericano, más que en otras partes del globo, la identidad regional -cuyo lazo con la cultura no queda por explicar- se relacione estrechamente con la historia "común" de las ciudades:

La identidad cultural latinoamericana se vincula a las raíces de la historia común de las ciudades de América Latina; a sus tradiciones, valores éticos, modo de vida, manifesta-
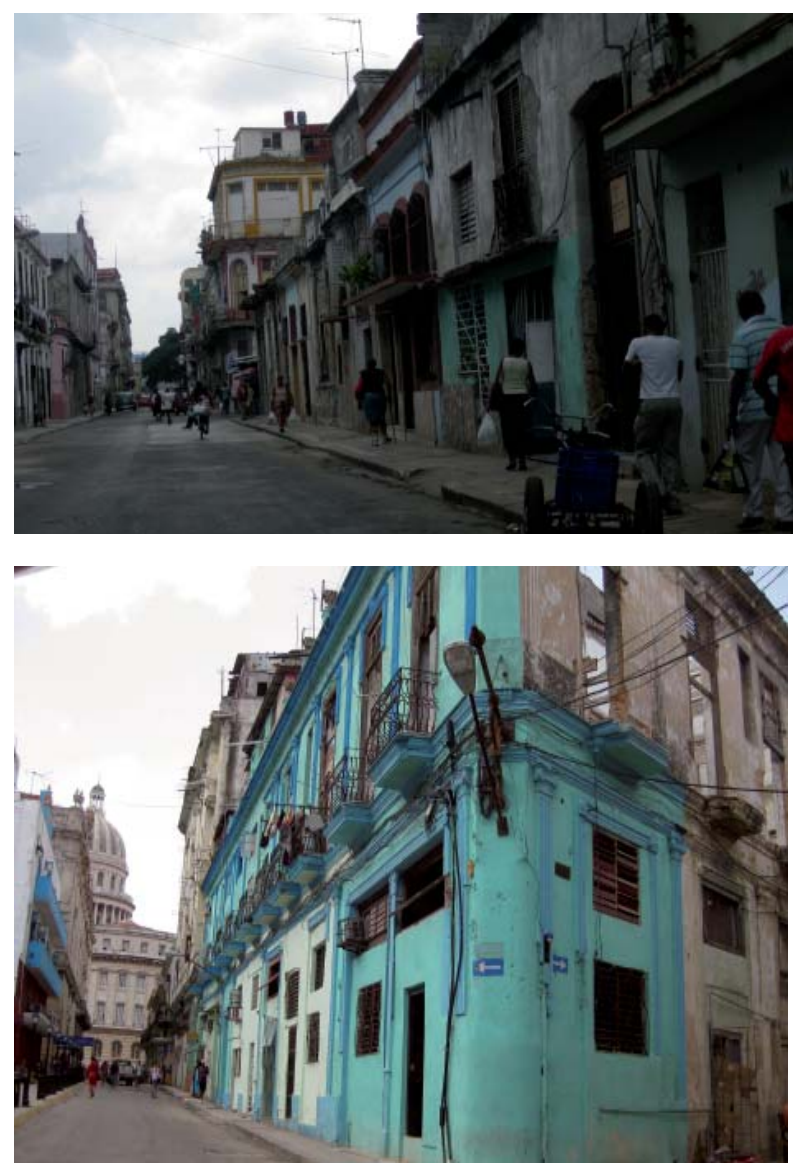

Imágenes 4, 5. Los barrios de La Habana Vieja y Centro Habana. Fuente: Janice Argaillot, julio de 2011

ciones funcionales, características específicas del marco físico-ambiental y la estructuración del mismo, problemática, y por sobre todos los aspectos, la idiosincrasia de nuestros pueblos. Por tales motivos nos corresponde conocerla, asimilarla, desarrollarla, divulgarla, defenderla, siendo esta identidad precisamente uno de los mayores objetivos que nos unen (Ruiz de Somocurcio, 1994, p. 108).

La ciudad es un guión entre las poblaciones latinoamericanas, y materializa su condición de pueblos, al expresar una identidad cultural formada de varios aportes. La estructuración de las ciudades y sus manifestaciones -ya sean funcionales o culturales- parecen ser la expresión y la materialización de una cultura compartida. En este sentido, la ciudad es la prueba de una cultura rica, hecha de rasgos comunes, de particularidades y particularismos, y hasta puede llegar a convertirse en el símbolo de una identidad asumida. A consecuencia, la existencia de barrios informales debe de desembocar en la creación de una nueva cultura, y el estudio de la ciudad no debe confinarse a la configuración material, sino abarcar una dimensión social y cultural, ya que en ella se puede leer la Historia:

La ciudad puede leerse [...] tanto desde los espacios formales como desde los informales: estos últimos operan desde los intersticios del sistema formal/oficial, constituyen su otra dimensión, y es donde se gestan -política y socialmente construidas- las prácticas subversivas y transgresoras. Estas prácticas informales son periféricas y centrales al mismo tiempo: se refieren a aquellos espacios libres del control oficial, las fisuras e intersticios, y, al 


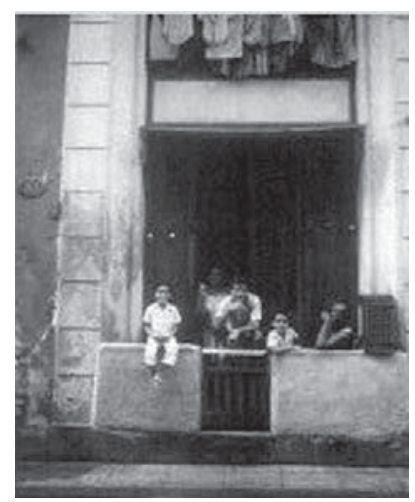

Imagen 6. Barbacoa en La Habana Vieja, 1999. Fuente: En Scarpaci Joseph L. (2004). Plazas and barrios: heritage tourism and globalization in the Latin America centro historic. Tucson: University of Arizona Press, p. 106

mismo tiempo, constituyen el locus de la vida privada y funcionan como un adhesivo de la fibra social. Son instrumentos de poder alternativo; mediante éstas, se desarroIlan formas y estrategias - económicas, de conocimiento y de cultura-que combaten aquellas formas de poder que niegan al individuo; en último término, configuran de una manera contestataria la vida pública, sea por oposición o por complementariedad, y subrayan la permanencia de tradiciones culturales [...] (Izquierdo, 2002, p. 23-24).

Respecto a esto, la llegada al poder de las tropas revolucionarias condicionó la relación de los habitantes a sus lugares de residencia:

Al considerar las estrategias de la vivienda de la revolución cubana, hay que reconocer otro fenómeno de los años sesenta, paralelo a los ambiciosos proyectos de construcción [...]. A mediados de la década de 1960 el éxodo de la acomodada clase media-alta de Cuba se había dado casi por completo. Los prósperos emigrantes dejaron en Cuba un enorme inventario de viviendas de alta calidad que luego se subdividió y fue ocupado por nuevos residentes de acuerdo a una racional y económica política de vivienda, ya sea por intervención del gobierno, o, más frecuentemente, por apropiación informal (Freeman, 2010, p. 33).

Las fuertes olas migratorias de los principios de la Revolución dejaron espacios vacíos, muy rápidamente llenados por los que se quedaron. Lo de insinuarse en los intersticios parece haber sido elevado al rango de práctica cultural.

La informalidad urbanística provoca y acarrea a la vez una informalidad más global; informalidad que los habitantes sienten en todos los niveles de su vida, fuertemente ligada a prácticas subversivas y transgresoras, que tienen repercusiones en las manifestaciones y producciones culturales. Una vez más, estas prácticas que se sitúan fuera de lo común, de lo aceptado y aceptable se construyen contra y en paralelo de la sociedad formal. Precisamente, se definen como informales por su insinuación en espacios abandonados de lo que se presenta como la ciudad normal, o sea de la ciudad institucional. A la naturaleza no le gusta el vacío, y los intersticios libres se llenan de nuevas prácticas, generadoras de cohesión social entre personas que viven la misma exclusión. Aquí, el punto importante es que las prácticas culturales informales hacen salir sus practicantes de la periferia para ponerlos al centro. Efectivamente, mediante éstas, el individuo sale de la masa, el excluido se relaciona con un grupo, y expresa una identidad propia, individual, pero representativa de toda una franja de la población que se quiere ignorar. De tal modo, se puede decir que las prácticas culturales nacidas y vividas en los barrios informales ayudan a sus practicantes a sentirse parte de un mundo, y a no verse únicamente como rechazados o marginados.

Estas prácticas no sólo vienen relacionadas a la religión o al arte, también se relacionan con el día a día. Así, el vivir juntos, la educación de los hijos o la propia elevación de los barrios informales son partes integrantes de éstas: Surge una técnica compuesta de elementos culturales propios de la dinámica de la informalidad, como son: la forma de construir individual y comunalmente, la utilización de materiales reciclados y la composición con mampuestos en arcilla y concreto; todo esto implantado en un lugar (Hernández Castro, 2006, p. 142).

Los barrios informales son además el sujeto de numerosas obras de artes y creaciones artísticas o literarias: In Havana [...] it is the construction that Cuban art critic Gerardo Mosquera calls indoor favelas that have marked the city to the point of becoming the subject of songs, short stories and novels -by the Cuban music group Los Van Van and by writers such as Reinaldo Arenas, Pedro Juan Gutiérrez, and Antonio José Ponte (Del Real et al., 2011, p. 69). La informalidad es la base de una cultura para los que la experimentan, pero también una fuente de inspiración para los que no la viven. Esto demuestra su fuerza, y las numerosas preguntas que hace surgir. Confirma que la informalidad no es un estatuto -social, político, cultural- aceptado como tal, sino que como lo formal, provoca interrogantes. Interesa a los intelectuales y artistas justamente porque no es nada común, porque supone cierto misterio, y desde un punto de vista artístico, la ciudad informal no fue rechazada por la ciudad formal, sino que ella es la que rechaza los códigos morales y sociales de la ciudad institucional. La informalidad se relaciona pues con cierta libertad, cierta independencia de espíritu, e incluso puede ser vista como la expresión de un deseo del individuo de escaparse de las pautas del mundo formal.

A ese respecto, la autonomía es una característica esencial de la construcción informal: [...] en el hábitat informal la técnica constructiva es posible a partir de la autogestión y autoproducción de la vivienda. Los componentes son: el lugar, los materiales y las relaciones de la comunidad [...] (Hernández Castro, 2006, p. 142). Se trata pues de una autonomía parcial, ya que la comunidad es importante. Frente a la ciudad formal, los barrios informales reivindican cierta libertad, que sólo puede existir gracias a cierta solidaridad entre sus habitantes.

La informalidad parece ligada a la identidad, hasta tal punto que las barbacoas llegan a ser presentadas como una nueva expresión de la cubanidad y del amor del pueblo cubano a la libertad: Barbacoas, therefore, represent a new type of cubanidad in light of the historic evolution [...]. They capture creativity, and their distribution is significant; in 2004, they were more than 17.000 in Habana Vieja municipality alone. We argue that these lofts constitute a new frontier in Cuba. They represent how households conquer unclaimed spaces in a real estate market that is restrictive [...] (Scarpaci \& Portela, 2009, p. 187). Quizás se trate de una nueva frontera cultural entre lo oficial y lo marginal, que como cualquier otra frontera se pueda trasgredir. Sea lo que sea, la dimensión vertical supuesta 
por las barbacoas ofrece nuevo espacio, de cierta manera nuevo horizonte, y constituye un nuevo espacio de expresión cultural para los cubanos (Scarpaci et al., 2009, p. 187).

Además, insinuarse en los intersticios vacíos de la ciudad ya es tomar una posición. Desde esta posición física, se reclama una posición en la sociedad. En efecto, colonizar espacios no reclamados -o sea lugares desertados, lugares de desinterés para las autoridades y los habitantes de la ciudad formal- es reclamar algo; es demandar por la justicia, la igualdad, el respeto. Así, lo de conquistar nuevos espacios, o espacios abandonados, desusados -y esto es importante puesto que el espacio no se roba, no era posesión de nadie-, llega a formar parte de la cultura, e incluso se convierte en una expresión cultural frente a las dificultades. Ir adonde los demás no quieren ir es posicionarse respecto al Otro, y a consecuencia marcar un paso hacia el autodescubrimiento. Se observa otra vez aquí que la condición ligada a la informalidad de un barrio no es de manera necesaria una condición penosa; al contrario puede ser asumida como una posición frente al conjunto de la sociedad, y como parte de una identidad.

Sin embargo, cabe subrayar que la informalidad y marginalidad pueden influir en la percepción de la cultura por parte de la ciudad formal. Desde afuera, se puede considerar que el arte procedente de barrios informales tiene menos importancia, menos fuerza, menos potencia. Así, la ciudad formal es la que sigue teniendo el poder, la que sigue imponiendo sus normas, como lo hicieron en su tiempo los conquistadores. Salir de las reglas impuestas por la ciudad formal es convertirse en un ser anormal, subnormal e inferior:

En una exploración no exhaustiva encontramos términos como: sectores populares, sectores marginales, sectores subnormales, sectores periféricos, asentamientos precarios, asentamientos populares, hábitat popular, ciudad popular o, simplemente, sectores pobres de las ciudades. [...] Es interesante señalar cómo los distintos términos identifican ciertas características, pero también ciertas posiciones; desde lo subnormal e informal, haciendo una clara referencia a una valoración negativa (no son normales ni formales), hasta los que expresan ubicación: periferia. También hay las miradas que pretenden ser técnicas o economicistas: asentamientos precarios o sectores pobres urbanos, que si bien señalan una de las características más importantes, no es la única ni tampoco es una condición clara y evidente para todos (¿pobre con relación a qué?) (Hernández García, 2008, p. 17).

Ya hemos subrayado que la multiplicidad de términos para designar la ciudad informal demuestra cierta inquietud que desemboca en la necesidad para la ciudad formal de verbalizar, de poner palabras sobre un mundo desconocido - puesto que muy a menudo, lo desconocido se ve como oculto, y da miedo. Si la informalidad inquieta el espacio formal de la ciudad, no puede ser por otra cosa que porque tiene cierto poder.

Asimismo, la ciudad informal no es un mero espacio que se desarrolla fuera de lo habitual. Es un lugar poblado, e incluso vivido por seres y comunidades. De este modo, la informalidad y lo de vivir en barrios informales impacta la vida cotidiana, al mismo tiempo que caracteriza la entrada del individuo y de la colectividad en los cambios mundiales, y en los procesos globales:
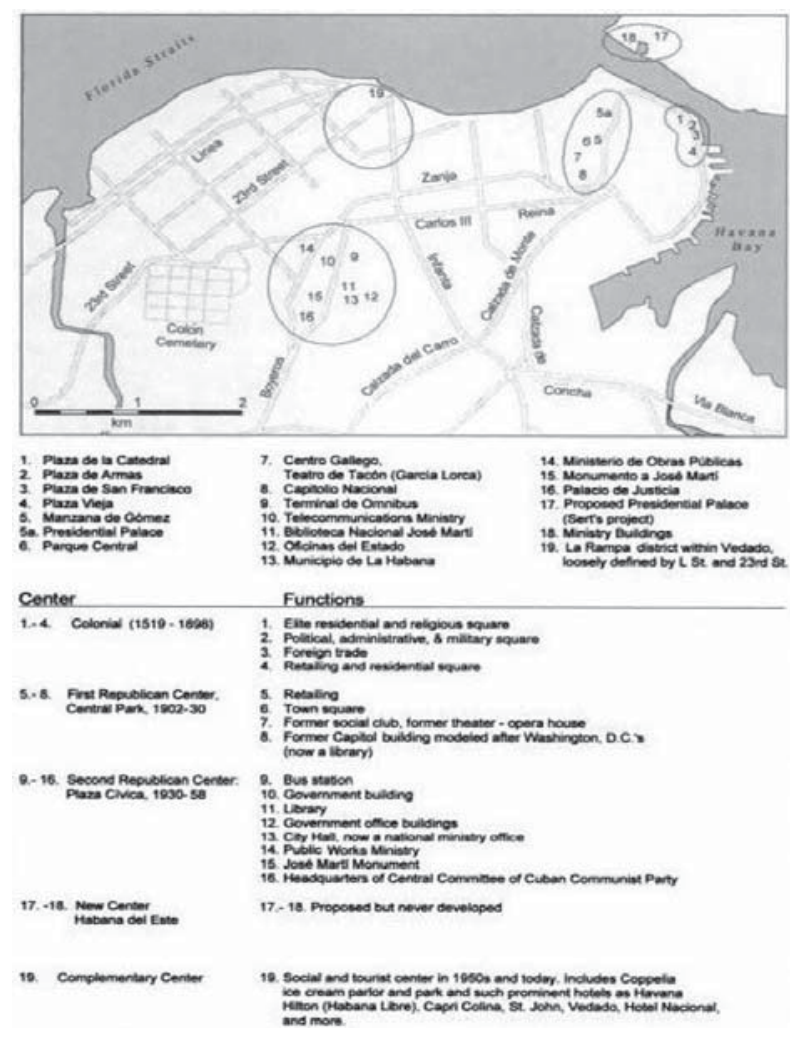

Imagen 7. Distribución de la parte central de la ciudad de La Habana. Fuente: En Scarpaci, Joseph L. Segre Roberto. Coyula Mario. (2002). Havana: two faces of the Antillean metropolis. Chapel Hill: University of North Carolina Press, p. 87

[...] la globalización de las economías y el ingreso de las tecnologías de información y comunicación a la vida colectiva e individual de las personas están determinando la calidad de vida de las mismas. Sin embargo, estas dos circunstancias han entrado de manera diferencial a los habitantes del mundo y causan mayor polarización entre quienes tienen acceso a estos servicios y quienes no lo tienen, tanto a nivel global (entre países) como local (entre habitantes de la misma ciudad) (Hernández García, 2008, p. 13).

Obviamente, los habitantes de la ciudad informal no tienen el mismo acceso que los de la ciudad formal a los nuevos medios de comunicación y a la tecnología, por falta de recursos, y por constituir un espacio al margen, no conectado al resto de la sociedad. Lo insólito aquí es que esa falta de conexión no ocurra por falta de nexos físicos. En efecto, como lo hemos subrayado, en la Habana, los barrios informales se encuentran hasta en el corazón de la ciudad formal. Para decirlo de otro modo, existe una pared virtual, intangible entre estas dos ciudades, que viven al lado la una de la otra. Esto no puede sino acentuar aún más las dicotomías y desigualdades, y la informalidad parece una vez más producir informalidad, a pesar de que ella nazca a veces de lo formal. Los habitantes de los barrios informales corren el peligro de quedarse al margen ya no sólo de la vida de su ciudad -ya que a pesar de todo son habitantes de La Habana- sino también de los procesos más globales que conoce el planeta. Si todos estos procesos no tienen única y necesariamente buenos aspectos, no pueden ser ignorados; la universalización supone otras formas de comunicación, y lo de no dominarlas puede ser dañino. 
Además, se constata que en los barrios informales tiene lugar una asimilación de varias culturas, pero también que a veces las culturas no logran mezclarse para conformar una identidad, sino que sólo se yuxtaponen. Esto origina el problema de sentirse excluido hasta del barrio informal, y el ser que no se siente vinculado a su comunidad no puede actuar a favor de ella. A modo de ejemplo, el barrio Santa Fe (en el extremo occidental de La Habana) conoció problemas relacionados a la llegada de inmigrantes, portadores de nuevas culturas:

desde los años cincuenta, pero sobre todo a partir de los setenta, [...] vio complicarse [...] su caracterización demográfica cuando se produjo el asentamiento de migrantes de otras zonas del país en las márgenes de un terreno cenagoso en el extremo oeste del poblado, lo que ha dado lugar a un barrio conocido como Bajo de Santana. Esta evolución histórica marca a Santa Fe con un sello contradictorio. Por un lado, se trata de una comunidad que históricamente preserva un sentido de pertenencia y que se asume como distinta respecto a otras comunidades cercanas y al propio municipio en que está enclavada. Pero por otro lado, la yuxtaposición de grupos poblacionales diferentes, portadores de tradiciones y rasgos culturales propios, ha configurado un espacio local en el que habitan más de 21 mil personas marcadas por una diversidad de modos de vida y aspiraciones a la que no ha podido sustraerse la práctica política en la zona [...] (Dilla Alfonso \& Fernández Soriano \& Castro Flores, 1999, p. 102).

Se ve que los barrios informales se constituyen como espacios apartes de la ciudad en su conjunto, pero también del municipio en el que se elevan, y que no siempre se relacionan con otros barrios informales. No parecen respetar los códigos, incluso los más locales, y cada uno tiene su propia cultura, lo que representa un desafío para los arquitectos interesados en trabajar en éstos: Como se ve, no es un problema menor el de la intensificación de la identidad cultural de cada comunidad o su contrario, el de su pérdida o dislocación. Para el ejercicio profesional de los arquitectos, [...] el reforzamiento de la identidad cultural de los pueblos o comunidades mediante el atinado proyecto y edificación de sus espacios habitables representa una meta de cuyo logro depende su propia realización como profesional (Vargas Salguero, 2005, p. 140). La construcción informal no se incorpora a la ciudad preexistente tras estudios de diseño. Se añade a lo existente, sin buscar ni la harmonía ni la lógica. Por eso a veces se ve como un agrego comparable a una enfermedad.

El hábitat informal también condiciona la identidad del individuo y la comunidad como espacio de vida social y colectiva. Los arquitectos juegan un papel en la conformación de la identidad cultural de los habitantes, pero estos últimos, al elegir o verse obligados a vivir en barrios informales, también tienen un rol de primer orden en la creación, recreación, consolidación o dilución de su identidad y de su cultura.

La cultura de los barrios informales viene acompañada de normas, no impuestas por las autoridades políticas oficiales, sino impulsadas desde los propios barrios informales. Sale a las claras que, si los que viven en barrios informales rechazan las reglas de la ciudad formal, no quieren huir de toda forma de normas: Se reconocen, entonces [...], el sistema de relaciones transformadoras entre la sociedad, el contexto o lugar y los elementos con dinámicas propias de una cultura urbana transformadora, en una permanente expresión de identidad y pertenencia (Hernández Castro, 2006, p. 144).

Por otra parte, notamos que como cualquier otra cultura, la del barrio de Santa Fe conoció un choque, más que un encuentro, a la llegada de extranjeros. El mestizaje que supuestamente deriva de la convivencia de personas de horizontes diferentes en barrios informales no desemboca de manera obligatoria en un encuentro cultural. Esto es la prueba fehaciente de la existencia de una cultura -que la ciudad formal ya no puede denegar a los barrios informales- y testimonia el apego de los habitantes de los barrios informales ya no sólo a su espacio de vida, sino también a dicha cultura así como a su identidad.

No obstante, hay que decir que la marginalidad actúa la mayoría de las veces como un factor de cohesión, y en ella también se crean nuevos códigos sociales:

Los 12.500 habitantes de Atarés ocupan un espacio de 28 hectáreas, lo que supondría una alta densidad poblacional de 45 mil habitantes por kilómetro cuadrado. La larga existencia de Atarés [ubicado en Cerro] como un barrio capitalino pobre con rasgos de marginalidad ha reforzado el sentido de pertenencia expresado en rituales, símbolos y jerarquías informales, buena parte de ellos provenientes de las religiones afrocubanas (santería, palo monte, abakuá) y de una intensa vida cultural (Dilla et al., 1999, p. 104).

Las culturas consideradas durante siglos como inferiores, folclóricas (en el sentido peyorativo del término) y a consecuencia marginadas -aquí las religiones afrocubanas- ayudan a configurar y estructurar la cultura actual de los barrios informales. El sentido de pertenencia a un espacio de vida común es sinónimo de conexión e intercambio entre los individuos de lo que ya es una comunidad.

\section{CONCLUSIÓN}

La Habana informal es al fin y al cabo estrechamente relacionada a su semejante formal. Si las dos ciudades parecen divididas, y ofrecen la imagen de dos espacios que viven ignorándose, los barrios informales sólo se denominan así por oposición a las áreas formales. Además, estos barrios se encuentran en numerosos lugares de la capital, y no se concentraron en sus afueras, lo que significa que la ciudad formal no rechazó totalmente a su gemela informal. De este modo, el espacio informal se acerca al institucional, y si ambos mundos no logran conectarse, tampoco se puede decir que son espacios físicamente demarcados y bien delimitados.

En segundo lugar, es necesario recordar que los problemas de los que viven en barrios informales no se limitan a problemas materiales. La insalubridad y la precariedad de las construcciones informales son un punto importante, pero no deben esconder los problemas relacionados a la identidad. En efecto, las condiciones de vida y el lugar de residencia influyen en la identidad personal de cada individuo, pero también ayuda (o no) a conformar una identidad colectiva, de la que puede nacer la solidaridad y el enfoque de un futuro común y compartido. Este punto es de suma importancia si se considera que una de las tareas de la Revolución cubana fue, y sigue siendo la (re)construcción de una identidad que sea a la vez nacional y respetuosa de los particularismos.

En fin, es de notar que la cultura informal no es nada inferior, y que los habitantes de los barrios marginados no se contentan con vivir fuera de las normas. Los códigos que se establecen en estos es- 
pacios son reflejo y prueba a la vez de la cultura que se desarrolla en paralelo. Para decirlo de otro modo, el espacio informal es un espacio de reflexión para los habitantes de la ciudad formal y para las autoridades, pero también un espacio de creación cultural.

Escuchar a los habitantes ya podría ser una solución a numerosos problemas. No pensar el barrio informal en término de diferencias, de problemas, sino intentar mejorar las condiciones de vida de sus habitantes sin querer obligarlos a incorporarse a la ciudad formal mediante la deconstrucción material de su vivienda, o sea la deconstrucción inmaterial de lo que son: Comment travailler avec les "bidonvillards", les "informels" sans les détruire, leur permettre d'améliorer leurs conditions d'habitat sans leur imposer les nôtres, sans institutionnaliser leur dynamisme au profit du pouvoir, d'une nouvelle ségrégation sociale et culturelle? (Gossé, 1991, p. 54).

\section{BIBLIOGRAFÍA}

BOTíN, Vicente. Bassets, Luís. (2009). Los funerales de Castro. Barcelona: Editorial Ariel.

DE LA FUENTE, Alejandro. (2001). A Nation for all: race, inequality, and politics in twentieth-century Cuba. Chapel Hill: University of North Carolina Press.

DEL REAL, Patricio. SCARPACI, Joseph. (2011). Barbacoas: Havana's new inward frontier. En Birkenmaier Anke, Whitfield Esther (Ed.), Havana beyond the ruins: cultural mappings after 1989 (pp. 53-72). Durham: Duke University Press.

DILLA ALFONSO, Haroldo. FERNÁNDEZ SORIANO, Armando. CASTRO FLORES, Margarita. (1999). Movimientos comunitarios en Cuba: un análisis comparativo. Cuban Studies, 28, pp. 100-124.

FERNÁNDEZ, Armando. (2007). Conflictos, vulnerabilidad y manejo de recursos naturales y energía en la región del Caribe. En Serbín Andrés (Ed.), Paz, conflicto y sociedad civil en América Latina y el Caribe (p. 309-352). Barcelona: Icaria Editorial.

FREEMAN, Belmont. (2010). Housing the Revolution: Cuba 1959-1969. Caribbean Modernist Architecture, 34, pp. 18-33.

GAJA I DÍAZ, Fernando. (2005). Revolución informal, crisis ecológica y urbanismo. Valencia: Editorial Universidad Politécnica de Valencia.

GOSSE, Marc. H. (1991). Espaces et développement. En Gossé Marc. H. Brunfaut Marc. Villes et architecture: essai sur la dimension culturelle du développement (pp. 29-56). Paris: Karthala.

HAMBERG, Jill. (2011). The "slums" of Havana. En Birkenmaier Anke, Whitfield Esther (Ed.), Havana beyond the ruins: cultural mappings after 1989 (pp. 73-105). Durham: Duke University Press.

HERNÁNDEZ CASTRO, Nieves Lucely. (2006). La conformación del hábitat de la vivienda informal desde la técnica constructiva. Bogotá: Universidad Nacional de Colombia.

HERNÁNDEZ GARCÍA, Jaime. (2008). Arquitectura, participación y hábitat popular. Bogotá: Pontificia Universidad Javeriana.

IZQUIERDO, Yolanda. (2002). Acoso y ocaso de una ciudad: La Habana de Alejo Carpentier y Guillermo Cabrera Infante. San Juan de Puerto Rico: Isla Negra Editores.

RODRÍGUEZ RUIZ, Pablo. ESTÉVEZ MEZQUÍA, Claudio. CAÑET IGLESIAS, Tania. (2008). Familia y matrimonio en la pobreza y la marginalidad. En Vera Ana, Robichaux David (Ed.), Familias y culturas en el espacio latinoamericano (pp. 239-278). México: Universidad Iberoamericana / La Habana: Centro de Investigación y Desarrollo de la Cultura Cubana Juan Marinello.
RUIZ DE SOMOCURCIO, Jorge. (1994). Problemas y posibilidades de la gestión urbana de las grandes ciudades en América Latina. En Puncel Chornet, Alfonso, Las ciudades de América Latina: problemas y oportunidades (pp. 111-126). Valencia: Universitat de València.

SCARPACI, Joseph L. SEGRE, Roberto. COYULA, Mario. (2002). Havana: two faces of the Antillean metropolis. Chapel Hill: University of North Carolina Press.

SCARPACI, Joseph L. PORTELA, Armando H. (2009). Cuban landscapes: heritage, memory and place. New York: Guilford Press.

SEFIL, Marc. (2010). Les Noirs à Cuba au début du XXe siècle, 1898-1933 : marginalisation et lutte pour l'égalité. Paris: L'Harmattan. 280 p.

SEGRE, Roberto. (2003). Arquitectura antillana del siglo XX. La Habana: Arte y Literatura; Bogotá: Universidad Nacional de Colombia.

--_. (2005). Tres décadas de reflexiones sobre el hábitat latinoamericano. Bogotá: Universidad Nacional de Colombia.

TORRES TOVAR, Carlos Alberto. (2008). Reflexiones sobre hábitat y vivienda en Colombia, 1990-2008. En Yory, Carlos Mario. Rodríguez García, César. Pensando "en clave" de hábitat: una búsqueda por algo más que un techo (pp. 132-181). Bogotá: Universidad Nacional de Colombia.

VARGAS SALGUERO, Ramón. (2005). Globalización, neoliberalismo y práctica arquitectónica. En Salazar González Guadalupe (Ed.), Teoría de la Arquitectura: Lo Local y lo Global: Escuelas Regionales de México (pp. 135143). México: Universidad Autónoma de San Luis Potosí. 